(1)

CrossMark

\title{
Long-term volume-targeted pressure-controlled ventilation: sense or nonsense?
}

\author{
Maria Paola Arellano-Maric ${ }^{1,2}$, Cesare Gregoretti ${ }^{3}$, Marieke Duiverman ${ }^{2,4}$ and \\ Wolfram Windisch ${ }^{2}$
}

Affiliations: ${ }^{1}$ Dept of Pneumology, Pontificia Universidad Católica de Chile, Santiago, Chile. ${ }^{2}$ Dept of Pneumology, Cologne Merheim Hospital, Kliniken der Stadt Köln gGmbH, Witten/Herdecke University, Faculty of Health/School of Medicine, Cologne, Germany. ${ }^{3}$ Dept of Biopathology and Medical Biotechnologies (DIBIMED), Section of Anesthesia, Analgesia, Intensive Care and Emergency. Policlinico P. Giaccone. University of Palermo, Palermo, Italy. ${ }^{4}$ Dept of Pulmonary Diseases, University Medical Center Groningen, Groningen Research Institute of Asthma and COPD (GRIAC), University of Groningen, Groningen, The Netherlands.

Correspondence: Wolfram Windisch, Dept of Pneumology, Cologne Merheim Hospital, Kliniken der Stadt Köln $\mathrm{gGmbH}$, Witten/Herdecke University, Faculty of Health/School of Medicine, Ostmerheimer Strasse 200 , D-51109 Köln, Germany. E-mail: windischwakliniken-koeln.de

@ERSpublications

The NIV-ventilator automatisation trend: careful titration process, ideally under sleep studies, is what matters! http://ow.ly/iXai30bNQx8

Cite this article as: Arellano-Maric MP, Gregoretti C, Duiverman M, et al. Long-term volume-targeted pressure-controlled ventilation: sense or nonsense? Eur Respir J 2017; 49: 1602193 [https://doi.org/10.1183/ 13993003.02193-2016].

ABSTRACT The technology underlying the development of novel ventilatory modes for long-term noninvasive ventilation of patients with chronic hypercapnia is continuously evolving. Volume-targeted pressure-controlled ventilation is a hybrid ventilation mode designed to combine the advantages of conventional ventilation modes, while avoiding their drawbacks. However, manufacturers have created different names and have patented algorithms and set-up variables, which can result in confusion for physicians and respiratory therapists. In addition, clear evidence for the superiority of this novel mode has not yet been established. These factors have most likely hindered more widespread use of this mode in clinical practice. The current review presents the rationale, working principles, characteristics and set-up recommendations associated with volume-targeted modes. In addition, it summarises the clinical and laboratory studies that have challenged this mode.

This article has been amended according to the correction published in the July 2017 issue of the European Respiratory Journal.

This article has supplementary material available from erj.ersjournals.com

Received: Nov 072016 | Accepted after revision: March 172017

Conflict of interest: Disclosures can be found alongside this article at erj.ersjournals.com

Copyright @ERS 2017 


\section{Introduction}

A worldwide increase in the use of long-term noninvasive ventilation (NIV) in patients with chronic hypercapnic respiratory failure in various clinical settings has occurred over the past 30 years [1-3]. This has led to a boost in the manufacture of ventilators with continuously developing novel ventilatory modes, as well as the recruitment of new technologies aimed at better patient-ventilator synchrony [4].

In 1992, a new ventilatory mode named "volume-assured pressure-support ventilation" was introduced into the market, with the aim of combining the advantages of conventional volume- and pressure-controlled ventilation [5]. Since then, many manufacturers have developed their own patented volume-targeted systems; overall, they can be described as pressure-controlled systems that aim to ensure the average level of a predetermined tidal volume $(V T)$ or alveolar ventilation ( $\left.V^{\prime} A\right)$. This mode is, therefore, an adaptive dual-targeting mode. According to different mathematical algorithms, this means that adjustments in inspiratory pressure (first target) take place over several breaths until the ventilator delivers the target $V$ T or $V^{\prime}$ A (second target). Thus, the term chosen for the purpose of the current review article is "volume-targeted pressure-controlled ventilation" (VTPCV).

The adaptive characteristics of VTPCV should permit the ventilator to properly react to changes in pulmonary impedance (i.e. body position or pulmonary mechanics) and maintain effective ventilation. Hence, setting unnecessarily high fixed inspiratory pressures is presumably avoided. This explains why, although VTPCV was initially conceived for invasive mechanical ventilation [5], its principal use has been in the care of patients with chronic conditions, such as neuromuscular diseases, obesity hypoventilation syndrome (OHS) and chronic obstructive pulmonary disease (COPD), which are all conditions in which comfortable ventilation is crucial for the patient's long-term adherence to treatment. Another proposed application for VTPCV modes is to facilitate the NIV titration process, as fine inspiratory pressure adjustments are made automatically [6, 7].

Although all of these theoretical benefits sound appealing, the few randomised controlled trials performed to date have shown mixed results. Additionally, ventilator manufacturers have created different names and set-up variables, which can result in confusion for physicians and respiratory therapists. Together, these factors have likely hindered more widespread use of this ventilation mode in clinical practice.

The current review presents the rationale, working principles, characteristics and set-up recommendations pertinent to volume-targeted modes that are available for home turbine-driven ventilators. Additionally, it summarises the clinical and laboratory studies that have challenged the validity of this mode.

\section{Rationale for volume-targeted pressure-controlled ventilation}

To comprehend the rationale behind the conception of VTPCV modes, the characteristics and drawbacks of conventional ventilation modes must first be understood (table 1 and supplementary material). In addition, particular situations that can compromise ventilation efficacy will be discussed.

Volume-controlled ventilation was the main mode used for home care in the early 1990s. In this mode, the variable that needs to be set is the inspiratory flow, and hence VT (tidal volume; the integration of flow over time). Meanwhile, pressure is the dependent variable resulting from the interaction between airway resistance and overall elasticity of the respiratory system. Conversely, the independent variable to be set in the pressure-controlled mode is pressure. Therefore, the resulting $V \mathrm{~T}$ and flow differ according to the impedance of the respiratory system.

Although the few studies that compared these two conventional ventilatory modes showed no differences in daytime blood gases or sleep quality $[8,9]$, pressure-controlled ventilation is by far the most extensively used NIV mode today [1] because of its relatively better leak compensation, pressure stability and patient tolerability (i.e. less gastrointestinal distension) $[9,10]$. Nevertheless, a major drawback of fixed values of bi-level pressure ventilation is that they do not guarantee a minimal VT. By contrast, VTPCV modes incorporate both pressure and volume targets to ensure constant ventilation, thus seeking to combine the advantages, and avoid the drawbacks, of the two classical NIV modes.

An important consideration for effective NIV therapy is the time when it is used. NIV is mostly used during sleep to counterbalance nocturnal hypoventilation and to relieve the need for the patient to use NIV during the day. There are numerous factors that contribute to hypoventilation during the sleep state, including the variable fall in respiratory drive and the modification of respiratory impedance between sleep stages, changes in body posture and increases in upper airway resistance [11]. Therefore, one of the critical aims of NIV is to provide gentle ventilation that adapts to these changing conditions and avoids sleep fragmentation.

As shown in figure 1, it is clinically common to find patients who are sufficiently ventilated while sleeping in the lateral position, whereas in the supine position, the applied fixed inspiratory and expiratory 
TABLE 1 Principal characteristics of conventional home care ventilation and the newer dual volume-targeted pressure-controlled noninvasive ventilation modes

Mode

\begin{tabular}{ll} 
Mode & Pressure-targeted \\
\hline Definition & APCV; PSV \\
Controlled variable & Inspiratory pressure \\
Baseline variable & ZEEP or a given EPAP\#
\end{tabular}

Trigger variable Pressure and flow in active respiration

Time in passive respiration

Cycling variable Time or a percentage of inspiratory flow decay (PSV or any other pressure-controlled flow-cycled mode)

$V$ 个

Alveolar ventilation Pressure ramp profile

Unintentional leak compensation

\section{Advantages}

Disadvantages

Used circuits
Variable according to airway impedance and patient effort

Influenced by patient effort and respiratory frequency Settableף

Good for mild to moderate leaks

Leak compensation

Flow adaptability to patient requirements

No guarantees for a certain $V_{T}$ Nonvented (exhalation valve) or intentional leak "vented"
circuit

\section{VTPCV}

V-targeted

Volume-targeted PSV targeting VT (e.g. AVAPS, Phillips Respironics ${ }^{\circledR}$; VT Smart Eove $\left.{ }^{\circledR}\right]$

Minimal and maximal inspiratory pressure (below or above EPAP possible)

ZEEP or a given EPAP\#

Alternatively, automatic EPAP adjustment

Pressure and flow in active respiration

Time in passive respiration

Time or a percentage of inspiratory flow threshold according to the manufacturer's algorithm

Inspiratory time depends on a given set $t \mid$, a $\left.t\right|_{\min }$ or an I/E ratio

A minimum average $V_{\top}$ is maintained

Influenced by patient effort and respiratory frequency Settable

Good for mild to moderate leaks

Guarantees a minimal average $V_{T}$

VT under- or over-estimation

Overshooting after a disruption cessation

Unvented or intentional leak "vented" circuit. AVAPS (Philips Respironics ${ }^{\circledR}$ ) uses only a "vented" circuit
Volume-targeted PSV targeting V'A

(e.g. iVAPS, ResMed $®$ )

Minimal and maximal inspiratory pressure

(above EPAP only)

ZEEP or a given EPAP

Alternatively, automatic EPAP adjustment

Only flow trigger is available in active respiration

Time in passive respiration

The percentage of inspiratory flow

threshold is always the first cycling factor

Time cycling depends on a given set $\left.t\right|_{\min }$

$$
\text { or }\left.t\right|_{\max }
$$

A $V_{T}$ value to achieve the preset $V^{\prime} \mathrm{A}$ is maintained

Maintained constant at set target $V^{\prime} A$

Settable

Good for mild to moderate leaks

Guarantees a minimal average $V^{\prime} \mathrm{A}$

V'A under- or over-estimation

Intentional leak "vented" circuit only

VTPCV: volume-targeted pressure-controlled ventilation; VT: tidal volume; V'A: alveolar ventilation; APCV: assisted pressure-controlled ventilation; PSV: pressure-supported ventilation; AVAPS: average volume assured pressure support; iVAPS: intelligent volume assured pressure support; EPAP: expiratory positive airway pressure; ZEEP: zero end expiratory pressure; $t$ : inspiratory time; I/E ratio: inspiratory/expiratory ratio. "\#: all ventilators using an intentional leak "vented" circuit have by default a certain level of EPAP. ": pressure ramp represents the time taken by the ventilator to reach the set inspiratory pressure. In a pressure-controlled flow cycled breath, the ventilator setting may modify inspiratory time and overall inspiratory flow. 


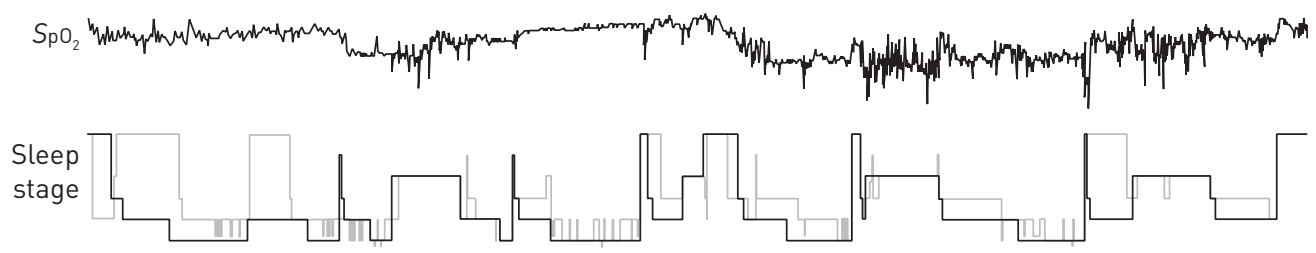



FIGURE 1 Polysomnography in a patient with obesity hypoventilation syndrome treated with conventional noninvasive ventilation (NIV) therapy lassisted pressure-controlled ventilation mode, $33 / 11 \mathrm{cmH}_{2} \mathrm{O}$, back-up respiratory rate 16 breaths per minute, inspiratory time $1.2 \mathrm{~s}$ ). The NIV therapy was adequate in the lateral posture (L). However, as soon as the patient turned to the supine position (S), a clear reduction in tidal volume occurred, leading to profound desaturation. No obstructive events were recognised under the measured expiratory positive airway pressure.

pressures are insufficient to avoid hypoventilation and/or upper airway closure. Theoretically, the volume-targeted ventilation algorithm should react appropriately to the changing respiratory mechanics, preventing residual hypoventilation and promoting patient-ventilator synchrony.

\section{Working principles of volume-targeted ventilation}

The aim of VTPCV modes is to automatically adjust ventilator parameters in order to guarantee a minimal tidal volume or alveolar ventilation. The machine's performance should be able to adapt to changing conditions in pulmonary mechanics as well as to unintentional leaks.

Each manufacturer has developed its own patented (and usually undisclosed) mathematical algorithm to ensure delivery of the preset $V$ T or $V^{\prime}$ A. This explains why, although all ventilators perform similarly, slight differences in individual ventilator responses still exist, and these may play a defining role when aiming for patient-ventilator synchrony.

The general working principles of VTPCV modes can be described as follows: the controlled variable is inspiratory pressure, which is constrained by the minimum and maximum inspiratory pressures set by the operator. Inspiration is initiated in the pressure-controlled mode, then once the machine receives feedback about the delivered volume, it "decides" whether to stay unchanged or to increase/decrease the inspiratory pressure in order to reach the dependent variable (the preset $V \mathrm{~T}$ ), before cycling on to expiration (figure 2). In the ResMed (Sydney, Australia) ventilation systems, their mode of iVAPS (intelligent Volume-Assured Pressure Support) means there is also an increase in respiratory rate to meet the target $V$ 'A if the patient's breathing frequency is less than two-thirds of the target respiratory rate. The cycling variable can be either time or the percentage of inspiratory flow decay (table 1). The baseline variable, expiratory positive airway pressure (EPAP), can be fixed or automatically adjusted within a range of minimum and maximum pressures set by the operator. The time span to reach the target $V_{\mathrm{T}} / V^{\prime} \mathrm{A}$ should be sufficiently rapid to avoid hypoventilation, but sufficiently smooth to avoid sleep disruption [12]. In this respect, the algorithm initially used to reach the set $V \mathrm{~T}$ within one breath is no longer valid $[5,13]$. Instead, slight and consecutive pressure support adjustments occur within several breaths, or over a minute, until the target $V \mathrm{~T}$ is reached. The current software programs for different VTPCV modes vary significantly in terms of speed adjustment to this response (supplementary material). Moreover, although some ventilators allow the operator to set the pressure support speed adjustment, others possess a fixed response rate, and still others react depending on how much the $V \mathrm{~T}$ is shifted from the programmed target $V$ T value. Using the iVAPS mode as an example, if alveolar ventilation is $50 \%$ below target, the rate of increase in pressure support is $0.35 \mathrm{cmH}_{2} \mathrm{O}$ per second. Conversely, at $200 \%$ of the ventilation target, the rate of decrease in pressure support is $0.5 \mathrm{cmH}_{2} \mathrm{O}$ per second.

In a different mode called AVAPS (Average volume-Assured pressure support; Philips Respironics, Greensburg, PA, USA), the patient's tidal volume is averaged over $1 \mathrm{~min}$ and the inspiratory pressure increases according to the speed rate set by the operator (from \pm 1 up to $5 \mathrm{cmH}_{2} \mathrm{O}$ per min). Meanwhile, the algorithm that offers the best combination of both efficient and comfortable ventilation remains unknown.

The ability of the ventilator's feedback system to accurately monitor the actual $V \mathrm{~T}$ is crucial for proper compensation by the software. It is widely, but incorrectly, thought that VTPCV algorithms are always based on the direct measurement of expiratory $V \mathrm{~T}\left(V \mathrm{~T}_{\text {exp }}\right)$. This requires pneumotacographic measurement 

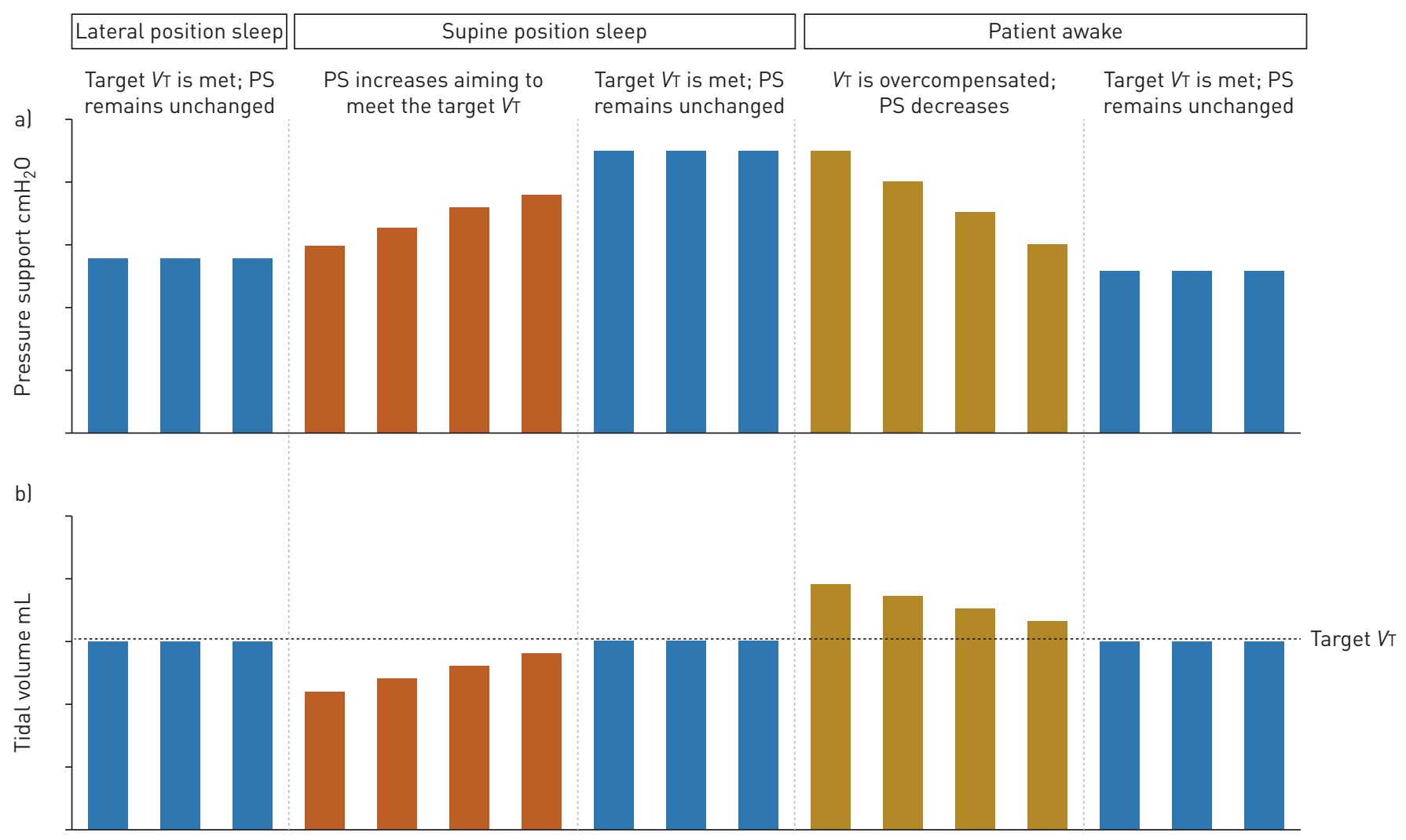

Time or number of breaths

FIGURE 2 a) Pressure-support changes in a specified time or number of breaths (depending on the ventilator's algorithm) applied to reach the target tidal volume $\left(V_{T}\right)$. b) Impact of the ventilator pressure support (PS) adjustment on $V_{T}$ in response to different respiratory mechanic situations caused by changes in body position and patient effort.

on the expiratory port of the ventilator; however, most devices do not allow the possibility of monitoring $V \mathrm{~T}_{\text {exp }}$, owing to an intrinsic feature of the circuit (i.e. ventilators with a single limb that are not provided with pneumotacographic measurement proximal to the airway) [14]. To the best of our knowledge, only two commercially available turbine-driven ventilators with a double-limb circuit (the Monnal T50 and Weinmann ventilators) use $V \mathrm{~T}_{\exp }$ as a $V \mathrm{~T}$ target for VTPCV modes. Of note, in the presence of an expiratory leak, this method may underestimate the real VT and overcalculate the delivered volume [14].

Another alternative for monitoring expired $V \mathrm{~T}$ is to estimate it, as in a vented intentional-leak circuit. Pressure and flow are measured inside the ventilator, taking into account the ventilator's turbine speed throughout the entire respiratory cycle, the intentional/unintentional leaks, and the detection of the beginning and end of inspiration. Subsequently, the ventilator is able to rebuild the patient's flow pattern and establish a "baseline" breathing pattern that corresponds to the patient's zero flow, to obtain an estimated $V \mathrm{~T}_{\text {exp }}$ equal to the inspiratory $V \mathrm{~T}\left(V \mathrm{~T}_{\mathrm{i}}\right)$. As a result, some ventilators accurately estimate $V \mathrm{~T}_{\text {exp }}$, even during constant leakage [15]. Special considerations about this important topic are discussed below.

How to set up a ventilator for volume-targeted pressure-controlled ventilation

A stepwise recommendation for how to set a ventilator using VT-targeted modes is shown in table 2. Please see supplementary material for a stepwise recommendation on how to set a ventilator using $V^{\prime}$ A-targeted modes.

\section{Tidal volume target setting}

One key variable for the effectiveness of $V$ T-targeted modes is how to define the target $V \mathrm{~T}$ value for each particular patient. If the set $V \mathrm{~T}$ is too low, the patient will probably be under-treated, whereas if it is too high, ventilation could become uncomfortable for the patient. It is also important to bear in mind that, although the set $V \mathrm{~T}$ will probably be reached, additional patient effort that contributes to pressure-supported breathing may lead to the set volume being exceeded. 
TABLE 2 How to set a ventilator on tidal volume (VT)-targeted mode

\section{1) Set the target VT value}

Until universal consensus is reached, the following approach is recommended: $8-10 \mathrm{~mL} \times \mathrm{kg}$ of IBW, adjusted according to pathology

IBW in men: $50.0+0.905 \times$ ((height in $\mathrm{cm})-152.4$

IBW in women: $45.5+0.905 \times$ (lheight in $\mathrm{cm})-152.4)$

2) Set the IPAP limits (the inspiratory pressure will be constrained between two pressures)

IPAP minimum: the lowest IPAP level that the patient should receive to maintain ventilation. It should be at least $4 \mathrm{cmH}_{2} \mathrm{O}$ higher than the EPAP.

IPAP maximum: the highest pressure the patient needs to maintain ventilation in challenging conditions such as deep sleep stages and supine body position. Factors such as the patient's pathology and ventilation tolerance, as well as mask seal should be taken into account.

3) Set the EPAP (baseline pressure)

A minimum per default level of EPAP is always present when using intentional leak configuration. Set an appropriate EPAP level according to the patient's underlying disease and optimally after a sleep study. Alternatively, some ventilators offer an automatic adjustable EPAP feature. Hereby, a minimal and maximal EPAP level must be set.

4) Set the pressure support adjustment speed rate

Some ventilators allow the operator to set the speed at which the VT should be reached (supplementary material). This should be selected based on disease severity and patient comfort.

5) Set the back-up respiratory rate (if appropriate)

IBW: ideal body weight (formula according to National Institutes of Health); IPAP: inspiratory positive airway pressure; EPAP: expiratory positive airway pressure.

Despite the number of considerations in place, the amount (millilitres) of $V \mathrm{~T}$ that needs to be calculated per kilogram of (patient) weight has still not been standardised. Previous clinical trials have used various approaches (table 3), rendering these trials incomparable and introducing a bias that may in part explain their inconsistent results. Regarding the patient's weight, the ideal body weight (IBW) is normally used in preference to actual body weight $(\mathrm{ABW})$ to calculate $V \mathrm{~T}$, otherwise there are concerns that the $\mathrm{ABW}$ in obese or underweight patients could lead to an excessive or insufficient $V$ T, respectively. Nevertheless, there is no universally accepted formula for calculating IBW. Moreover, comparison of three IBW formulas showed significant differences between them, both for men and for women [16].

Finally, to add even more confusion, the ventilator manufacturers recommend different rather than evidence-based formulas to define the target VT. A further point to be considered is the patient's underlying pathology. An analysis of downloaded data from 150 home ventilators used by stable patients showed variability of $V \mathrm{~T}$ and minute volume values (possibly reflecting the different requirements) depending on the cause of the ventilatory failure [17]. In conclusion, the current heterogeneous calculation of $V \mathrm{~T}$ underscores the need for a consensus between clinicians, investigators and manufacturers to establish a standardised calculation for IBW and the target $V$ T value (in $\mathrm{mL} / \mathrm{kg}$ ) for every pathology.

An alternative approach to define $V \mathrm{~T}$ and minute volume settings is to use the autotitration function offered by V'A-targeted mode (iVAPS) ventilators. Firstly, the ventilator estimates the baseline $V^{\prime} \mathrm{A}$ following a 20-min learning period during spontaneous breathing under $4 \mathrm{~cm} \mathrm{H}_{2} \mathrm{O}$ when the patient is awake. Based on the patient's learned parameters, the software automatically defines the ventilator's settings to meet the determined target ventilation. However, applying a hypercapnic patient's daytime-learned $V$ 'A might be insufficient to overcome respiratory insufficiency [6, 7]. It is also important to note that previous work has shown that a greater number of operator adjustments in the autotitrating ventilator were needed to optimise ventilation compared with conventional ventilation treatment [7].

Manufacturers pledge that VTPCV modes could simplify the titration process, therefore being helpful in limited manpower settings. Nevertheless, it is important to bear in mind that more parameters need to be set and interpreted during VTPCV compared with conventional modes. Therefore, it is advisable to have a more highly trained team to handle these more complex hybrid modes and ensure their proper use.

\section{Pressure support window setting}

The ventilator either increases or decreases the level of pressure support, with the aim of achieving the set VT. Thus, minimal and maximal inspiratory positive airway pressure (IPAP) must be set to provide a pressure window that should be wide enough to let the algorithm work within proper limits. In this respect, the minimum pressure support setting should correspond to a safe level of $V \mathrm{~T}$ for the patient. Likewise, the maximum pressure support setting enables the ventilator to increase inspiratory pressures 


\section{TABLE 3 Clinical studies performed with volume-targeted pressure-controlled ventilation (VTPCV) mode for home mechanical ventilation (HMV)}

\begin{tabular}{|c|c|c|c|c|}
\hline Study & Year & Design & Target volume setting & Main VTPCV outcomes \\
\hline \multicolumn{5}{|l|}{ OHS } \\
\hline MASA et al. [34] & 2015 & $\begin{array}{l}\text { 2-month RCT VT targeted ventilation versus CPAP versus } \\
\text { lifestyle modification in recently diagnosed patients with } \\
\text { OHS }(n=221)\end{array}$ & $5-6 \mathrm{~mL} \cdot \mathrm{kg}^{-1}$ (actual weight) & $\begin{array}{l}\text { Similar improvements in: } \\
\text { Daytime } \mathrm{PaCO}_{2} \text { and } \mathrm{PaO}_{2} \\
\text { Daytime somnolence } \\
\text { Clinical symptoms } \\
\text { Sleep parameters by PSG } \\
\text { Only the } V \mathrm{~T} \text {-targeted ventilation group showed } \\
\text { significant improvements in: } \\
\text { Pulmonary function } \\
\text { 6MWT }\end{array}$ \\
\hline MuRPHy et al. [38] & 2012 & $\begin{array}{l}\text { 3-month RCT, single-blind, PSV versus VT-targeted } \\
\text { ventilation in HMV-naïve patients }(n=50)\end{array}$ & $\begin{array}{l}\text { 8-10 } \mathrm{mL} \cdot \mathrm{kg}^{-1} \mathrm{IBW}+\text { individualised } \\
\text { manual titration under PG }\end{array}$ & $\begin{array}{l}\text { Similar improvements in: } \\
\text { Daytime } \mathrm{PaCO}_{2} \\
\text { Health-related quality of life } \\
\text { Weight loss } \\
\text { Diurnal sleepiness }\end{array}$ \\
\hline JANSSENS et al. [30] & 2009 & $\begin{array}{l}\text { 1-day crossover RCT fixed BiNIV on S/T mode versus } \\
\text { VT-targeted ventilation in HMV-experienced patients } \\
(n=12)\end{array}$ & $7-8 \mathrm{~mL} \cdot \mathrm{kg}^{-1}$ of actual weight & $\begin{array}{l}V_{\text {T-targeted ventilation applied higher IPAP }} \\
\text { (mean } 2.6 \mathrm{cmH}_{2} \mathrm{O} \text { ) than fixed BiNIV } \\
\text { Higher } V_{\top} \text { and } V^{\prime} \mathrm{E} \\
\text { Subjective discomfort and worse sleep quality }\end{array}$ \\
\hline StORRE et al. [39] & 2006 & $\begin{array}{l}\text { 6-week crossover RCT fixed BiNIV versus V'A-targeted } \\
\text { ventilation in HMV-naïve patients }(n=10)\end{array}$ & $\underset{\substack{(\mathrm{n}=5) \\
7 \mathrm{~mL} \cdot \mathrm{kg}^{-1}}}{\mathrm{IBW}(\mathrm{n}=5), 10 \mathrm{~mL} \cdot \mathrm{kg}^{-1} \mathrm{IBW}}$ & $\begin{array}{l}V \text { T-targeted ventilation applied higher IPAP (mean } \\
4 \mathrm{cmH}_{2} \mathrm{O} \text { ) than fixed BiNIV } \\
\text { Similar improvements in: } \\
\text { Sleep quality measured by PSG } \\
\text { Daytime } \mathrm{PaCO}_{2} \text { and } \mathrm{PaO}_{2} \\
\text { Health-related quality of life }\end{array}$ \\
\hline \multicolumn{5}{|l|}{ COPD } \\
\hline StORRE et al. [45] & 2014 & $\begin{array}{l}\text { 3-month open-label study of stable Hi-NIV ventilated } \\
\text { patients switched to two different VT-targeted ventilation } \\
\text { strategies }(n=14)\end{array}$ & $\begin{array}{l}8 \mathrm{~mL} \cdot \mathrm{kg}^{-1} \text { of IBW or } 100 \% \text { of individual } \\
V_{\text {T during Hi-NIV }}\end{array}$ & $\begin{array}{l}\text { Similar effects on: } \\
\text { Sleep parameters by PSG } \\
\text { Health-related quality of life } \\
\text { Weight loss } \\
\text { Diurnal sleepiness } \\
\text { Nocturnal } \mathrm{PtcCO}_{2} \text { improvement }\end{array}$ \\
\hline OsCROFt et al. [44] & 2014 & $\begin{array}{l}\text { Randomised, parallel-group trial comparing 3-month } \\
\text { V'A-targeted ventilation versus pressure-preset NIV in } \\
\text { HMV-naïve patients ( } n=40 \text { ) }\end{array}$ & $\begin{array}{l}V^{\prime} \text { E was recorded by the device during a } \\
1-\mathrm{h} \text { trial of PSV at } 15 \mathrm{mmHg} \text {; the } \\
\text { mean value of } V^{\prime} E \text { was set as the } \\
\text { target } V^{\prime} E\end{array}$ & $\begin{array}{l}\text { Similar improvements in: } \\
\text { Daytime } \mathrm{PaCO}_{2} \text { and } \mathrm{PaO}_{2} \\
\text { Mean overnight oximetry } \\
\text { Compliance after } 3 \text { months } \\
\text { Pulmonary function } \\
\text { Exercise capacity } \\
\text { Health-related quality of life } \\
\text { Fewer titration days were needed in } V \text { 'A-targeted mode }\end{array}$ \\
\hline
\end{tabular}


TABLE 3 Continued

EKKERNKAMP et al.

[43]

2013 6-week open-label crossover RCT, Hi-NIV versus
V'A-targeted ventilation in HMV-experienced patients
$(n=14)$

$$
(n=14)
$$

OsCRoft et al. [46] 2010 8-week crossover RCT, V'A-targeted ventilation versus pressure-preset NIV in HMV-experienced patients $(n=24$
CRISAFUlLI et al. [47]
2009 5-day crossover RCT, PSV versus VT-targeted ventilation in HMV-naïve patients ( $n=9$ )

\section{Neuromuscular}

KATZBERg et al. [57] 2013 Pilot, self-controlled study in naïve patients with ALS starting NIV on VT-targeted ventilation mode $(n=12)$

Crescimanno et al. 2011 3-day crossover RCT in NIV-experienced patients with [13]
Specified as an assessment of $V^{\prime} E$ during Simi

accordingly

According to patient's diurnal measured $V^{\prime} E$ lresulted in mean $V^{\prime} E$ of $11 \pm 3.6 \mathrm{~L}$

$8 \mathrm{~mL} \cdot \mathrm{kg}^{-1}$ of IBW

in:

6-7 $\mathrm{mL} \cdot \mathrm{kg}^{-1}$ of IBW, plus further adjustment (not specified)

\footnotetext{
8-10 $\mathrm{mL} \cdot \mathrm{kg}^{-1}$ of IBW according to patient comfort.
}

Sleep quality measured by PSG

Daytime $\mathrm{PaCO}_{2}$ and $\mathrm{PaO}_{2}$

More restful home sleep (self-reported) when under $V$ 'A-targeted ventilation

Health-related quality of life

Exercise capacity

Comfort and tolerability

$\mathrm{PaCO}_{2}$ was $3 \mathrm{mmHg}$ lower with PSV; $P_{\mathrm{aO}}$ was

$2.5 \mathrm{mmHg}$ higher with PSV

(Careful interpretation is advised due to persistent

hypercapnia in both groups.) Similar improvements in:

Daytime $\mathrm{PaCO}_{2}$ and $\mathrm{PaO}_{2}$

Daily compliance

Better self-reported sleep quality under $V_{T}$-targeted ventilation

(No protocol for the $V T$-targeted ventilation titration.) Improvement in:

Sleep time spent $<90 \%$ oxygen saturation $(30$ versus $19 \%)$

No improvements in:

Sleep quality as measured by PSG

$\mathrm{AHI}$, which remained abnormal $(6.3 \pm 8) ; 57 \%$ of the events were central

Similar effects on:

Median Vte

Daytime $\mathrm{PaCO}_{2}$ and $\mathrm{PaO}_{2}$ versus $V_{T}$-targeted ventilation $(n=28$ )
Majority of patients preferred the standard NIV modes

Only $11 \%$ preferred $V_{T}$-targeted ventilation

$89 \%$ of patients under $V_{T}$-targeted ventilation presented IE versus $0 \%$ in the other two modes 
TABLE 3 Continued

\section{Study}

JAYE et al. [6]

Year Design

2009 1-month crossover RCT, V'A-targeted ventilation versus

fixed BiNIV on ST mode in HMV-experienced patients

$(n=20)$

ORLIKOWSKI et al.

2009 2-day crossover RCT, pressure-preset NIV versus

investigator-designed $V T$-targeted ventilation algorithm in

experienced HMV patients with nocturnal air leaks ( $n=14$ )

\section{Target volume setting}

Automatically determined by ventilator's

intelligent software

Not disclosed

\section{Main VTPCV outcomes}

(Careful interpretation is advised due to persistent

hypercapnia under both modes. V'E was significantly

lower on VT-targeted ventilation.) Similar effects on:

Pulmonary function

Majority of sleep parameters measured by PSG

Respiratory muscle strength

Mean nocturnal $P_{\mathrm{tcCO}}$ was significantly higher on

$V$ 'A-targeted ventilation

$V_{T}$-targeted ventilation applied higher IPAP (mean

$4 \mathrm{~cm} \mathrm{H}_{2} \mathrm{O}$ ) than BiNIV

Similar effects on:

Sleep quality as measured by PSG

Daytime $\mathrm{PaO}_{2}$

Mean overnight oximetry

Under BiNIV:

$\mathrm{PaCO}_{2}$ was $>7 \mathrm{mmHg}$ higher

$V_{T_{i}}$ was $300 \mathrm{~mL}$ lower

OHS: obesity hypoventilation syndrome; RCT: randomised controlled trial. $V$ T. tidal volume. CPAP: continuous positive airway pressure: $P$ aco 2 arterial carbon dioxide tension; $P_{a 0_{2}}$ arterial oxygen tension: PtcCO: transcutaneous partial pressure of carbon dioxide; PSG: polysomnography; 6MWT: 6-min walk test: IBW: ideal body weight: PSV: pressure support ventilation; PG: polygraphy; NIV: noninvasive ventilation; BiNIV: bi-level NIV; V'E: minute volume; V'A: alveolar ventilation; IPAP: inspiratory positive airway pressure; S/T: spontaneous/timed mode; COPD: polygraphy; NIV: noninvasive ventilation; BiNIV: bi-level NIV; V'E: minute volume; V'A: alveolar ventilation; IPAP: inspiratory positive airway pressure; S/T: Spontaneous/timed mode; COPD:
chronic obstructive pulmonary disease; Hi-NIV: high-intensity NIV; ALS: amyotrophic lateral sclerosis; AHI: apnoea-hypopnoea index; Vte: expiratory tidal volume; aPCV: assisted pressure-controlled ventilation; IE: ineffective effort; $\mathrm{PtCO}_{2}$ : transcutaneous carbon dioxide tension; $V_{\mathrm{i}}$ : inspiratory tidal volume. 
and compensate for drops in $V \mathrm{~T}$ in cases of leakage or reduced inspiratory effort (i.e. while sleeping) [14, 16]. Additionally, if the IPAP minimum is too high, the set $V \mathrm{~T}$ will be exceeded, whereas if the IPAP maximum is set too low, the set $V \mathrm{~T}$ will not be reached.

A pragmatic approach is to set a wide range for the pressure support window initially, and subsequently carry out pressure reductions according to clinical observations, ventilator software data and usual monitoring parameters (blood gases, sleep studies including oximetry/transcutaneous carbon dioxide tension).

\section{EPAP pressure setting}

As mentioned above, the EPAP level can be a fixed value adjusted in response to clinical observations or following measurements during polygraphy or polysomnography. Alternatively, some ventilators (e.g. AVAPS-AE, Philips ${ }^{\star}$; iVAPS-autoEPAP, ResMed ${ }^{\oplus}$; PRISMA 30 ST, Löwenstein Medical, Weinmann ${ }^{\circledR}$ ) also allow the EPAP level to be automatically adjusted to maintain upper airway patency between constrained minimum and maximum pressures set by the operator. For this purpose, most new devices use snore detection in combination with flow detection. Apnoea and hypopnoea are typically defined as a reduction in ventilation below a percentage of recent breathing for at least $10 \mathrm{~s}$, with varying methods of flow analysis. The distinction between central or obstructive events includes cardiogenic pulsation testing and device-generated pressure oscillations [18]. Although these methods probably provide a good approach against upper airway obstruction, there are still concerns about their accuracy [19]. Caution is advised until specific studies evaluating the automated EPAP function are published [20].

\section{Pitfalls of volume-targeted pressure-controlled ventilation modes \\ Response to leaks}

Leaks are divided into "intentional" (occur by default from the mask exhalation port in vented circuit configuration) and "unintentional" (occur between the skin and the mask, or in the case of nasal mask usage, via the opened mouth) [21]. Unintentional leaks are almost unavoidable during NIV, and can hinder its success, leading to patient-ventilator asynchrony, sleep disturbance and hypoventilation [22-25].

Therefore, ventilators and their individual modes should have the capacity to cope with unintentional (and variable) leaks. This depends on the accuracy of the leak calculation, the circuit configuration and the corresponding output of the system. Intentional and unintentional leaks in vented circuit configuration are computed over the entire respiratory cycle. Unintentional leaks are not considered to be part of the delivered $V \mathrm{~T}$; therefore, the delivered $V \mathrm{~T}$ should remain constant in the presence of a linear (not random) unintentional leak. In the unvented circuit configuration (circuit provided with inspiratory/expiratory valves), $V \mathrm{~T}_{\mathrm{i}}$ values are computed at the beginning of inspiration, so that in the presence of an unintentional leak, the delivered $V \mathrm{~T}$ will be overestimated. In other words, the increased flow generated by the leak is included in the integral of overall flow used to calculate $V \mathrm{~T}_{\mathrm{i}}$. This means that the higher the leak, the higher the considered $V \mathrm{~T}_{\mathrm{i}}$.

In a study evaluating the built-in software of seven home ventilators in vented configuration, CONTAL et al. [26] showed that in the presence of leaks, VT was underestimated by all the devices, and the bias (range 66-236 mL) increased with higher insufflation pressures.

Presented with this difficulty, several laboratory studies have investigated the capability of home ventilators using the VTPCV mode to maintain the preset VT under different conditions. CARLUCCI et al. [25] showed that, regardless of the circuit configuration, these ventilators were able to maintain the set $V \mathrm{~T}$ in the absence of leaks in normal, obstructive and restrictive lung modes. They coped acceptably well with moderate to high leaks, albeit only when used in conjunction with a vented circuit configuration. Conversely, all devices in nonvented circuit configurations undercompensated for $V \mathrm{~T}$ in the presence of leaks. A further study by KHIRANi et al. [14] resulted in similar findings. Indeed, all ventilators failed to guarantee the set $V \mathrm{~T}$ in the presence of leaks when used with a "true" expiratory valve.

The effectiveness of the double-limb circuit was also tested. Surprisingly, two of the devices did not measure expiratory $V \mathrm{~T}$, and were thus unable to compensate for unintentional leaks. Another ventilator with a double-limb circuit overcompensated for $V \mathrm{~T}$ because it equated expiratory $V \mathrm{~T}$ with its target $V \mathrm{~T}$. This excessive delivery of $V \mathrm{~T}$ was due to the presence of expiratory leaks that led to the underestimation of the real $V \mathrm{~T}_{\mathrm{i}}$. LUJÁN et al. [16] found that five tested ventilators in "vented" configuration underestimated real $V \mathrm{~T}$ (range from -21.7 to $-83.5 \mathrm{~mL}$ ). Indeed, increasing leakage was the main factor that influenced $V$ T (range from $-2.27 \%$ to $-5.42 \%$ for each $10 \mathrm{~L} \cdot \mathrm{min}^{-1}$ leak flow increase). In addition, the same group found in two further studies that the introduction of random unintentional (especially inspiratory) leaks affected the performance of commercial ventilators with vented single-limb circuits at a magnitude that could have important clinical implications [27, 28]. 


\section{Overshooting}

Defined as an inadequate increase in $V \mathrm{~T}$ of $>20 \%$, overshooting can occur in some ventilators after the removal of an unintentional leakage $[25,29]$. Overshooting reflects the inability of the ventilator to rapidly respond to sudden respiratory changes and adequately decrease airway pressure, and can lead to patientventilator asynchrony and sleep discomfort $[14,30]$. Moreover, in cases of prompt amelioration of respiratory mechanics, or following the removal of an unintentional leak, VT-targeting NIV modes may cause overshooting and hyperventilation because both respiratory rate and alveolar ventilation are not controlled. This could lead to unfavourable conditions such as lower arterial carbon dioxide tension $\left(\mathrm{PaCO}_{2}\right)$ levels, which, in turn, could decrease the patient's respiratory effort and cause patient-ventilator asynchrony, periodic breathing, oxygen desaturation and microarousals [29, 31, 32]. In addition, an increase in dynamic hyperinflation could arise in patients with obstructive disease. Another concern is potential gastric air intake, which can lead to discomfort, vomiting and aspiration [29].

\section{Role of volume-targeted pressure-controlled ventilation in clinical practice Obesity hypoventilation syndrome}

Published randomised control trials have shown that the majority of patients with OHS can be treated successfully with CPAP therapy [33-35]. However, it is recommended that bi-level positive-pressure ventilation is applied in more complex cases such as severe obesity, concomitant moderate-severe COPD and sleep-related hypoventilation with low apnoea-hypopnoea index (lone OHS), and when high initial $\mathrm{PaCO}_{2}$ levels exist or there is a need for high CPAP pressures [36, 37].

Only a few trials have compared fixed bi-level versus VTPCV NIV modes in patients with OHS [30, 38, 39]. Murphy et al. [38] performed a randomised controlled trial in 46 newly diagnosed patients with OHS with body mass index $50 \pm 7 \mathrm{~kg} \cdot \mathrm{m}^{-2}$, comparing VT-targeted versus fixed bi-level NIV. At 3 months, both groups showed significant improvement in gas exchange, daytime somnolence and quality of life, and no clinically important differences between the groups were found. Importantly, this trial used a strict NIV titration protocol guided by polygraphy and transcutaneous $\mathrm{CO}_{2}$ measurements to warrant optimal settings in both groups [38]. Simply put, the key messages to be retrieved from this study are: 1) both conventional and VT-targeted modes can successfully treat patients with OHS; 2) a careful and individualised titration process to deliver appropriate pressures and $V \mathrm{~T}$ plays a deciding role in achieving the potential optimal therapy benefits, independent of the chosen mode [38, 40]; 3) controlled ventilation for more than $50 \%$ of the night led to a greater decrease in diurnal and nocturnal $\mathrm{CO}_{2}$, and improved health-related quality of life, irrespective of the mode used.

Of note, no trials have compared the long-term effects of the different positive-pressure modes on cardiovascular comorbidity, quality of life or mortality [36].

\section{COPD}

NIV use for at least $5 \mathrm{~h}$ per day is a known factor for determining improvement in gas exchange [41] and survival in patients with chronic hypercapnic COPD [2]. As NIV is preferably applied during the night, it makes sense to establish which mode is most comfortable for the patient. Moreover, patients with COPD can present a broad range of sleep-related disturbances, which include poor sleep quality and sleep disordered breathing [42].

In a crossover trial in ventilator-experienced patients with COPD, the impact on sleep quality of a $V^{\prime}$ A-targeted mode versus standard fixed bi-level NIV was compared. Polysomnographic measurements for each mode had similar outcomes. However, during the 6-week period of home ventilation, there was a slightly subjective improvement in restfulness with the V'A-targeted mode [43].

Regarding other important outcomes, the few published studies have failed to show any additional advantage of VTPCV modes over standard fixed bi-level pressure support ventilation [43-47]. Of note, the optimal method for defining the target $V \mathrm{~T}$ value in COPD remains unknown. OsCrofT et al. randomised 40 patients with COPD to VT-targeted or fixed bi-level pressure-support ventilation (PSV) treatment, with NIV titration performed during the daytime by an experienced team of nurses. After 3 months, no significant differences between groups were found in gas exchange, quality of life or compliance. In this study, the mean IPAP pressure in the fixed PSV group was $28(27.3-30) \mathrm{cmH}_{2} \mathrm{O}$ versus the permitted IPAP maximum of $25 \mathrm{cmH}_{2} \mathrm{O}$ in the $V$ T-targeted group. This could explain why a shorter titration process was required in the VT-targeted mode (3.3 versus 5.2 days) [44].

\section{Neuromuscular disease}

Overall, neuromuscular diseases account for around $10-51 \%$ of the indications for home mechanical ventilation $[3,48,49]$. The aims for initiating NIV in these patients are to prolong survival, ameliorate symptoms, decrease hospitalisation rate and improve quality of life [50]. However, there is still discussion 
between experts as to which mode is preferable. In addition, there are special considerations to be taken into account for neuromuscular diseases. These patients might be particularly sensitive to NIV and normally, there is a progressive course of the disease including diaphragmatic weakness and increase in NIV requirement (to $24 \mathrm{~h}$ per day). The decrease in muscular effort makes these patients especially prone to desaturations and hypoventilation in cases of important pressure variations $[13,51]$. This may lead to glottis closure in patients with amyotrophic lateral sclerosis (ALS) [52], for example.

Although the VTPCV modes are especially recommended by the manufacturers for the group of neuromuscular diseases, their application in daily practice still appears to be limited. According to a registry in Belgium and France, out of 209 patients with neuromuscular disease, 122 (59\%) were using a volume-controlled mode, while $82(39 \%)$ were using a pressure-controlled mode and only five (2\%) were using a VTPCV mode [53].

None of the few available randomised trials in neuromuscular diseases has compared long-term VTPCV modes with conventional bi-level NIV [54]. Regarding conventional modes, in a retrospective study of 144 ventilated patients with ALS, survival was similar whether volume- or pressure-preset ventilation was applied, but volume-preset NIV achieved better gas exchange and symptom relief [51].

Beyond the NIV mode chosen, probably the most important step to achieve ventilation goals is meticulous titration and optimisation of NIV parameters, ideally assessed using sleep studies [52, 55]. VRIJSEN et al. [56] performed meticulous titration (using fixed bi-level PSV) during 3 nights of polysomnography in patients with ALS. On the final night of titration, and following 1 month of home mechanical ventilation, there was a significant improvement in sleep quality, carbon dioxide and nocturnal oxygen. By contrast, in a study in which titration (using a $V^{\prime}$ A-targeted mode) was performed during daytime, guided only by patient comfort, no improvement in sleep efficiency, sleep arousals or sleep architecture was seen [57]. These unmet aims are probably not due to the use of a particular ventilatory mode, but rather due to the lack of an optimal titration process that led to insufficient ventilatory settings.

\section{Conclusions and future considerations}

Volume-targeted pressure controlled ventilation is a hybrid ventilation mode that aims to combine the advantages of conventional ventilatory modes. Unfortunately, robust evidence is not yet available to show its superiority over the traditional set-point targeting ventilators. However, clinical experience as well as scientific evidence suggest that individual patients might benefit from these adaptive modes, even though a general beneficial effect remains to be established. This must certainly be balanced against the pitfalls and complications associated with VTPC modes. Therefore, VTPC mode should cautiously be considered as an alternative mode for treating chronic respiratory insufficiency, for example in cases of residual hypoventilation under conventional modes. Hereby, taking into account that proper parameter settings are crucial for ventilation effectiveness. Therefore, ventilator's parameters should ideally be assessed under polygraphic/polysomonagraphic measurements. Probably the most important factor to provide an effective tailored NIV therapy to each patient is to manage several ventilator platforms and to understand the working principles of each device. In regards to the trend of ventilator's automatization, manufactures, clinicians and patients should work as a team towards translating artificial intelligence into tangible advances in patient care.

\section{References}

1 Lloyd-Owen SJ, Donaldson GC, Ambrosino N, et al. Patterns of home mechanical ventilation use in Europe: results from the Eurovent survey. Eur Respir J 2005; 25: 1025-1031.

2 Köhnlein T, Windisch W, Köhler D, et al. Non-invasive positive pressure ventilation for the treatment of severe stable chronic obstructive pulmonary disease: a prospective, multicentre, randomised, controlled clinical trial. Lancet Respir Med 2014; 2: 698-705.

3 Garner DJ, Berlowitz DJ, Douglas J, et al. Home mechanical ventilation in Australia and New Zealand. Eur Respir J 2013; 41: 39-45.

4 Chatburn RL, Mireles-Cabodevila E. Closed-loop control of mechanical ventilation: description and classification of targeting schemes. Respir Care 2001; 56: 85-98.

5 Amato MB, Barbas CS, Bonassa J, et al. Volume-assured pressure support ventilation. A new approach for reducing muscle workload during acute respiratory failure. Chest 1992; 102: 1225-1234.

6 Jaye J, Chatwin M, Dayer M, et al. Autotitrating versus standard noninvasive ventilation: a randomised crossover trial. Eur Respir J 2009; 33: 566-573.

7 Kelly JL, Jaye J, Rachel E, et al. Randomized trial of 'intelligent' autotitrating ventilation versus standard pressure support non-invasive ventilation: impact on adherence and physiological outcomes. Respirology 2014; 19: 596-603.

8 Tuggey JM, Elliot W. Randomised crossover study of pressure and volume non-invasive ventilation in chest wall deformity. Thorax 2005; 60: 859-864.

9 Windisch W, Storre JH, Sorichter S, et al. Comparison of volume- and pressure-limited NPPV at night: a prospective randomized cross-over trial. Respir Med 2005; 99: 52-59. 
10 Smith IE, Shneerson JM. A laboratory comparison of four positive pressure ventilators used in the home. Eur Respir J 1996; 9: 2410-2415.

11 Sowho M, Amatoury J, Kirkness JP, et al. Sleep and respiratory physiology in adults. Clin Chest Med 2014; 35: 469-481.

12 Carlucci A, Fanfulla F, Mancini M, et al. Volume assured pressure support ventilation - Induced arousals. Sleep Med 2012; 13: 767-768.

13 Crescimanno G, Marrone O, Vianello A. Efficacy and comfort of volume-guaranteed pressure support in patients with chronic ventilatory failure of neuromuscular origin. Respirology 2011; 16: 672-679.

14 Khirani S, Louis B, Leroux K, et al. Harms of unintentional leaks during volume targeted pressure support ventilation. Respir Med 2013; 107: 1021-1019.

15 Luján M, Sogo A, Pomares X, et al. Effect of leak and breathing pattern on the accuracy of tidal volume estimation by commercial home ventilators: a bench study. Respir Care 2013; 58: 770-777.

16 Linares-Perdomo O, East TD, Brower R, et al. Standardizing predicted body weight equations for mechanical ventilation tidal volume settings. Chest 2015; 148: 73-78.

17 Pasquina P, Adler D, Farr P, et al. What does built-in software of home ventilators tell us? An observational study of 150 patients on home ventilation. Respiration 2012; 83: 293-299.

18 Johnson KG, Johnson DC. Treatment of sleep-disordered breathing with positive airway pressure devices: technology update. Med Devices 2015; 8: 425-437.

19 Georges M, Adler D, Contal O, et al. Reliability of Apnea-Hypopnea Index measured by a home bi-level pressure support ventilator versus a polysomnographic assessment. Respir Care 2015; 60: 1051-1056.

20 Couillard A, Pepin JL, Rabec C, et al. Noninvasive ventilation: efficacy of a new ventilatory mode in patients with obesity-hypoventilation syndrome. Rev Mal Respir 2015; 32: 283-290.

21 Gregoretti C, Navalesi P, Ghannadian S, et al. Choosing a ventilator for home mechanical ventilation. Breathe 2013; 10: 395-408

22 Vignaux L, Vargas F, Roeseler J, et al. Patient-ventilator asynchrony during non-invasive ventilation for acute respiratory failure: a multicenter study. Intensive Care Med 2009; 35: 840-846.

23 Rabec C, Rodenstein D, Leger P, et al. Ventilator modes and settings during non-invasive ventilation: effects on respiratory events and implications for their identification. Thorax 2011; 66: 170-178.

24 Vrijsen $\mathrm{B}$, Chatwin $\mathrm{M}$, Contal $\mathrm{O}$, et al. Hot topics in noninvasive ventilation: report of a working group at the International Symposium on Sleep-Disordered Breathing in Leuven, Belgium. Respir Care 2015; 60: 1337-1362.

25 Carlucci A, Schreiber A, Mattei A, et al. The configuration of bi-level ventilator circuits may affect compensation for non-intentional leaks during volume targeted ventilation. Intensive Care Med 2013; 39: 59-65.

26 Contal O, Vignaux L, Combescure C, et al. Monitoring of noninvasive ventilation by built-in software of home bilevel ventilators. Chest 2012; 141: 469-476.

27 Luján M, Sogo A, Grimau C, et al. Influence of dynamic leaks in volume-targeted pressure support noninvasive ventilation: a bench study. Respir Care 2015; 60: 191-200.

28 Sogo A, Montanyà J, Monsó E, et al. Effect of dynamic random leaks on the monitoring accuracy of home mechanical ventilators: a bench study. BMC Pulm Med 2013; 13: 75

29 Fauroux B, Leroux K, Pépin JL, et al. Are home ventilators able to guarantee a minimal tidal volume? Intensive Care 2010; 36: 1008-1014.

30 Janssens JP, Metzger M, Sforza E. Impact of volume targeting on efficacy of bi-level non-invasive ventilation and sleep in obesity-hypoventilation. Respir Med 2009; 103: 165-172.

31 Toublanc B, Rose D, Glérant JC, et al. Assist-control ventilation vs. low levels of pressure support ventilation on sleep quality in intubated ICU patients. Intensive Care Med 2007; 33: 1148-1154.

32 Dempsey JA, Veasey SC, Morgan BJ, et al. Pathophysiology of sleep apnea. Physiol Rev 2010; 90: 47-112.

33 Piper AJ, Wang D, Yee BJ, et al. Randomised trial of CPAP vs bilevel support in the treatment of obesity hypoventilation syndrome without severe nocturnal desaturation. Thorax 2008; 63: 395-401.

34 Masa JF, Corral J, Alonso ML, et al. Efficacy of different treatment alternatives for obesity hypoventilation syndrome. Am J Respir Crit Care Med 2015; 192: 86-95.

35 Howard M, Piper A, Stevens B, et al. A randomised controlled trial of CPAP versus non-invasive ventilation for initial treatment of obesity hypoventilation syndrome. Eur Respir J 2014; 44: Suppl. 58, 4868.

36 Piper A. Obesity hypoventilation syndrome: weighing in on therapy options. Chest 2016; 149: 856-868.

37 Mandal S, Hart N. Respiratory complications of obesity. Clin Med 2012; 12: 75-78.

38 Murphy PB, Davidson C, Hind MD, et al. Volume targeted versus pressure support non-invasive ventilation in patients with super obesity and chronic respiratory failure: a randomised controlled trial. Thorax 2012; 67: $727-734$

39 Storre JH, Seuthe B, Fiechter R, et al. Average volume-assured pressure support in obesity hypoventilation: A randomized crossover trial. Chest 2006; 130: 815-821.

40 Windisch W, Storre JH. Target volume settings for home mechanical ventilation: great progress or just a gadget? Thorax 2012; 67: 663-665.

41 Struik FM, Lacasse Y, Goldstein R, et al. Nocturnal noninvasive positive pressure ventilation in stable COPD: a systematic review and individual patient data meta-analysis. Respir Med 2014; 108: 329-337.

42 McNicholas WT, Verbraecken J, Marin JM. Sleep disorders in COPD: the forgotten dimension. Eur Respir Rev 2013; 22: 365-375.

43 Ekkernkamp E, Storre JH, Windisch W, et al. Impact of intelligent volume-assured pressure support on sleep quality in stable hypercapnic chronic obstructive pulmonary disease patients: a randomized, crossover study. Respiration 2014; 88: 270-276.

44 Oscroft NS, Chadwick R, Davies MG, et al. Volume assured versus pressure preset non-invasive ventilation for compensated ventilatory failure in COPD. Respir Med 2014; 108: 1508-1515.

45 Storre JH, Matrosovich E, Ekkernkamp E, et al. Home mechanical ventilation for COPD: high-intensity versus target volume noninvasive ventilation. Respir Care 2014; 59: 1389-1397.

46 Oscroft NS, Ali M, Gulati A, et al. A randomised crossover trial comparing volume assured and pressure preset noninvasive ventilation in stable hypercapnic COPD. COPD 2010; 7: 398-403. 
47 Crisafulli E, Manni G, Kidonias M, et al. Subjective sleep quality during Average Volume Assured Pressure Support (AVAPS) ventilation in patients with hypercapnic COPD: a physiological pilot study. Lung 2009; 187: 299-305.

48 Veale D, Gonzalez-Bermejo J, Borel JC, et al. Initiation of long-term non-invasive ventilation at home: current practices and expected issues. Surveys from the CasaVNI working party. Rev Mal Respir 2010; 27: 1022-1029.

49 Nasiłowski J, Wachulski M, Trznadel W, et al. The evolution of home mechanical ventilation in Poland between 2000 and 2010. Respir Care 2015; 60: 577-585.

50 MacIntyre EJ, Asadi L, McKim DA, et al. Clinical outcomes associated with home mechanical ventilation: a systematic review. Can Respir J 2016; 2016: 1-8.

51 Sancho J, Servera E, Morelot-Panzini C, et al. Non-invasive ventilation effectiveness and the effect of ventilatory mode on survival in ALS patients. Amyotroph Lateral Scler Frontotemporal Degener 2014; 15: 55-61.

52 Gonzalez-Bermejo J, Perrin C, Janssens JP, et al. Proposal for a systematic analysis of polygraphy or polysomnography for identifying and scoring abnormal events occurring during non-invasive ventilation. Thorax 2012; 67: 546-552.

53 Lofaso $\mathrm{F}$, Prigent $\mathrm{H}$, Tiffreau V, et al. Long-term mechanical ventilation equipment for neuromuscular patients: meeting the expectations of patients and prescribers. Respir Care 2014; 59: 97-106.

54 Annane D, Orlikowski D, Chevret S. Nocturnal mechanical ventilation for chronic hypoventilation in patients with neuromuscular and chest wall disorders. Cochrane Database Syst Rev 2014; CD001941.

55 Fanfulla F, Carratù P. And the patient said: "Let me be able to breathe and dream". J Clin Sleep Med 2015; 11.

56 Vrijsen B, Testelmans D, Belge C, et al. Patient-ventilator asynchrony, leaks and sleep in patients with amyotrophic lateral sclerosis. Amyotroph Lateral Scler Frontotemporal Degener 2016; 17: 343-50.

57 Katzberg HD, Selegiman A, Guion L, et al. Effects of noninvasive ventilation on sleep outcomes in amyotrophic lateral sclerosis. J Clin Sleep Med 2013; 9: 345-351. 